\title{
Asymmetrical fatiguing of the gluteus maximus muscles in the elite short-track female skaters
}

\author{
Mariusz Konieczny ${ }^{1}$, Paweł Pakosz ${ }^{1 *}$ id and Mateusz Witkowski
}

\begin{abstract}
Background: According to research, fast skating on short distances increases functional asymmetry of leg muscles. As has been proven in many sporting disciplines, this asymmetry can increase the risk of injury. The aim of the study was to analyze the level of right and left myolectrical manifestations of fatigue asymmetry of gluteus maximus muscle in elite skaters on a short track and to compare this phenomenon to a control group. The muscles were chosen deliberately, due to their influence in maintaining the right position during training on ice.

Methods: The experiment compared a group of eight members of the Polish Women's National Team in short track with a group of eight non-training people. The subjects did the Biering-Sorensen test, in which sEMG (surface electromyography) signal frequency was measured in the gluteus maximus muscles during an isometric contraction. Myolectrical manifestations of fatigue slopes were analyzed with a ANOVA with repeated measures. In the skaters, the myolectrical manifestations of fatigue differed between the right and the left gluteus maximus muscles. All the skaters had higher myolectrical manifestations of fatigue in the right leg. This phenomenon was not observed in the non-training subjects, who on average had similar myolectrical manifestations of fatigue in both legs.
\end{abstract}

Results: Results showed that the right and the left muscles of the skaters in the experimental group differed in myolectrical manifestations of fatigue, but this difference was non-significant in the control group.

The subjects from the two groups did not differ in the myolectrical manifestations of fatigue of the left muscle, they did in the myolectrical manifestations of fatigue of the right muscle. The elite speed-track skaters had higher myolectrical manifestations of fatigue in the right muscle than the non-training subjects.

Conclusions: Training should thus be planned in a way that minimizes the risk of causing muscle myolectrical manifestations of fatigue asymmetry in skaters despite the typically asymmetrical muscle work during training on ice and competition, thus new training protocols should be developed or considered to decrease that asymmetry.

Trial registration: The tests were previously approved by the Bioethical Commission of the Chamber of Physicians in Opole. (Resolution No. 235 of 13 December 2016).

Keywords: Electromyography, Motor laterality, Short-track, Muscle myolectrical manifestations of fatigue

\footnotetext{
* Correspondence: p.pakosz@po.edu.pl

${ }^{1}$ Faculty of Physical Education and Physiotherapy, Opole University of

Technology, Prószkowska 76, 45-758 Opole, Poland

Full list of author information is available at the end of the article
}

(c) The Author(s). 2020 Open Access This article is licensed under a Creative Commons Attribution 4.0 International License, which permits use, sharing, adaptation, distribution and reproduction in any medium or format, as long as you give appropriate credit to the original author(s) and the source, provide a link to the Creative Commons licence, and indicate if changes were made. The images or other third party material in this article are included in the article's Creative Commons licence, unless indicated otherwise in a credit line to the material. If material is not included in the article's Creative Commons licence and your intended use is not permitted by statutory regulation or exceeds the permitted use, you will need to obtain permission directly from the copyright holder. To view a copy of this licence, visit http://creativecommons.org/licenses/by/4.0/ The Creative Commons Public Domain Dedication waiver (http://creativecommons.org/publicdomain/zero/1.0/) applies to the data made available in this article, unless otherwise stated in a credit line to the data. 


\section{Background}

Muscular asymmetry, especially in professional athletes, increases the risk of injury, as pointed out by various authors examining asymmetry of muscles in football players, basketball players, and people with spinal pains [1-4]. Surface electromyography is considered a reliable and credible tool for assessing the post-effort myolectrical manifestations of fatigue of muscles. In this kind of analysis, the most often used parameters of the sEMG signal are changes in amplitude scope and in the mean or median frequency of total capacity spectrum. In some studies however physical effort did not decrease the median frequency sEMG signal [5-8].

Many authors have used the Biering-Sorensen test to examine a myolectrical manifestations of fatigue level and determine differences in the muscular work of symmetrical muscles [9-11]. To meet the needs of analysing muscular myolectrical manifestations of fatigue in different body positions, various elements of the BieringSorensen test have been modified, such as body position and the time of conducting the test $[12,13]$.

The asymmetry of gluteus maximus muscles has been described in the literature most often in the contexts of walk and isolated positions [11, 14]. In short track, previous research has dealt with the muscular work of only one limb or with asymmetry in the myolectrical manifestations of fatigue of muscles during skating. Felser et al. studied athletes skating in a straight line and in curves [15]. Neuromuscular activation was higher in the right leg, while with the reduction in skating speed decreased neuromuscular activity, but only when skating in a straight line. This indicates that the right leg has higher activity during skating in curves. Studying athletes skating in a straight line and in curves during the subsequent laps, Hesford et al. found considerable asymmetry in oxygen supply to the two legs. The authors did not report effects of this asymmetry, but offered suggestions for training [16]. Stoter et al. showed that the bioelectric tension of muscles of speed skaters was correlated with speed at different sections of the track, but they did not analyse whether muscular asymmetry affected this phenomenon [17]. At present, the literature of the examined phenomenon contains analyses of muscle myolectrical manifestations of fatigue in many variants [18]. Non-invasive methods of determination of myolectrical manifestations of fatigue parameters also include surface electromyography (sEMG). Analysis of the sEMG signal frequency of the power spectrum provides useful information concerning local muscle myolectrical manifestations of fatigue $[7,19]$.

The idea behind the study was initiated by the coaches of the Polish National Team, worried about the asymmetry in the skaters and the related increased injury risk. Even though the coaches try to focus as much of the training as possible on symmetrical work, they stress that training on ice accounts for about $60 \%$ of the training volume and skating to the left is a typical asymmetrical work. Since the level of asymmetry varies from athlete to athlete, the coaches stress the importance of customised training, which would help them improve muscular symmetry in each athlete in an optimal way.

The main research hypothesis is that intensive shorttrack training leads to asymmetry of the gluteus maximus muscles. Thus, the paper aims to study the size of asymmetry in muscle activity and assess the difference in fatigability between the right and the left gluteus maximus muscles of the Polish Women's National Team in short track, and to compare this fatigability with that in non-training women.

\section{Methods \\ Participants}

Two research groups took part in the tests. The experimental group included eight female members of the Polish National Team in short track, with a mean age of $18.7 \pm 2.9$ standard deviation, mean height of $162.4 \pm 2.4$ $\mathrm{cm}$, and mean body weight of $57.2 \pm 5.9 \mathrm{~kg}$. The control group included eight female students active in sports (but not in speed skating), with a mean age of $20 \pm 0.9$, mean height of $169.1 \pm 4.1 \mathrm{~cm}$, and mean body weight of $68 \pm 4.2 \mathrm{~kg}$. These students were randomly selected from among female students of physical education at Opole University of Technology. The research was conducted during the training cycle, after a weekend break in training, to avoid the short-term effect of myolectrical manifestations of fatigue accumulation due to the training. The participants were informed about the purpose and course of tests and signed a consent to participate in the tests. The tests were approved by the Bioethical Commission of the Chamber of Physicians in Opole, Poland. In interviews conducted before the tests, all the respondents declared they were right-handed and right-legged in daily and sports activities (e. g., tossing a ball, kicking a ball, supporting with a foot during swinging). Furthermore, a kick-a-ball test (with three attempts) confirmed all the participants were right-legged, while the modified Edinburgh questionnaire confirmed they were righthanded [20].

\section{Procedures}

The sEMG signal frequency in the gluteus maximus muscles was examined in an isometric contraction using the position from the Biering-Sorensen test [11, 12]. To avoid too high loads for the skaters, the tests were stopped after $60 \mathrm{~s}$ of the contraction, and they were not continued until the subject was unable to hold the position because of muscle myolectrical manifestations of fatigue. The effectiveness of the myolectrical manifestations of fatigue test 
during a 60-s contraction was confirmed by Mutchler et al. [21]. During the test, the subjects were lying on a horizontal table on the abdomen, with the iliac crests aligned to the edge of the table and the lower limbs attached to the straps around the ankle joints. They were instructed to hold the body (head, shoulders, and torso), without support, horizontally to the ground as long as they could, with the arms crossed at the chest (Fig. 1).

\section{The EMG measurement}

In the test, a 16-channel EMG system (produced by NORAXON DTS) was used, which recorded signals with an accuracy of 16 bits at a sampling rate of $1500 \mathrm{~Hz}$. The bio-electric test of activity of the right and the left gluteus maximus muscles was carried out by the SENI AM methodology $[11,22]$. To improve the adherence of the electrodes, before the test, the hair was shaved and the skin was cleaned in the place where the electrodes were to be stuck. Surface electrodes $(\mathrm{Ag} / \mathrm{AgCl})$ were placed on the muscle between the movement point and the tendon attachment, along the longitudinal middle line of the muscle. Signal processing and EMG analysis were performed using NORAXON MR-XP 1.07 Master Editionx software.

Myolectrical manifestations of fatigue-related changes (frequency shift) in the frequency content were calculated for the raw EMG signal (Fig. 2) obtained during a static contraction. Unfiltered raw sEMG was analysed step-wise in $1000 \mathrm{~ms}$ increments over the selected portion of the measurement $(60 \mathrm{~s}$ in the Biering-Sorensen test). The mean frequency was calculated for each step using values based on the frequency power spectrum (calculated by a Prime Factor Fourier Transformation). A myolectrical manifestations of fatigue slope (being a regression coefficient from a linear regression line between the mean frequency and time) was estimated for each participant. The mean value of the slopes of these lines were analyzed with mixed ANOVA withinbetween interactions taking into account the side factor (left/right muscle) and the studied group (experimental, control). sEMG frequency power spectrum is expected to shift to lower frequencies during fatiguing contractions, and the mean frequency analysis can be used to estimate the magnitude of that shift. This phenomenon is well established for static contractions at constant load levels and believed to reflect local myolectrical manifestations of fatigue (Fig. 3.).

Technical specification of NORAXON DTS is as follows:

- basic noise of the device, below $1 \mathrm{uV}$ RMS,

- input impedance above 100 Momh,

- CMR (common signal rejection factor) greater than $100 \mathrm{~dB}$,

- sampling frequency $1500 \mathrm{~Hz}$,

- gain500.

\section{Statistical analysis}

The slopes representing the subjects' myolectrical manifestations of fatigue were analyzed with mixed ANOVA within-between interactions. The two groups (short track and control) constituted the betweensubject factor, and the two sides (left leg and right leg) constituted the within-subject factor. Since the interaction was significant, Tukey's post hoc tests were applied for pair-wise comparisons of the four factor combinations. For the analyses, a 0.05 significance level was used. All analyses were made in Statistica v. 13.1.

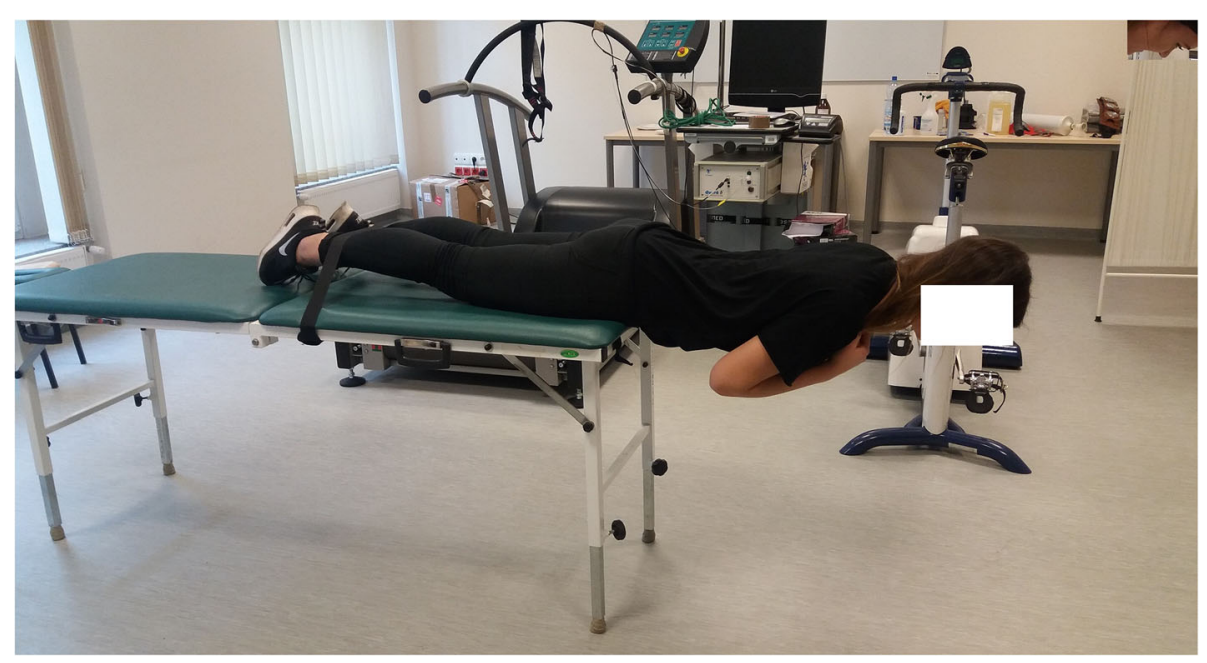

Fig. 1 Body position in the Biering-Sorensen test 


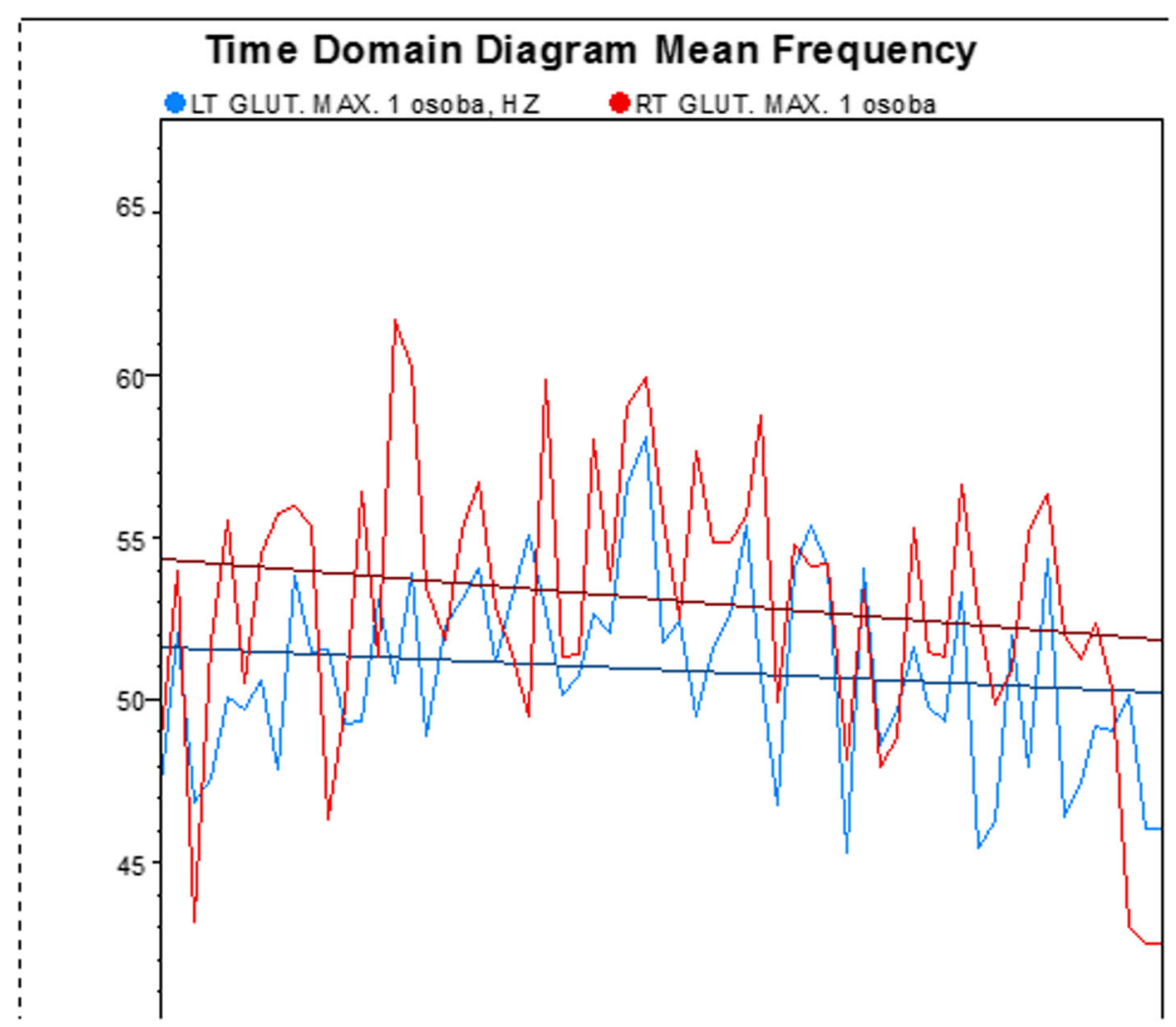

Fig. 2 Exemplary raw sEMG records during warm-up before testing the Biering-Sorensen test

\section{Results}

In the ANOVA, the main effect of the group was nonsignificant $(F(1,14)=2.964, p=0.107)$. The main effect of the side (right-left) of the muscle, however, was significant $(F(1,14)=20.323, p<0.001)$, and so was the group-by-side interaction $(F=(1,14)=6.111, p=0.0268)$
(Fig. 4). Tukey's tests (Table 1) showed that the right and the left muscles of the skaters (i.e., the subjects in the experimental group) differed in myolectrical manifestations of fatigue $(p=0.001)$; this difference was nonsignificant in the control group. The subjects from the two groups did not differ in the myolectrical

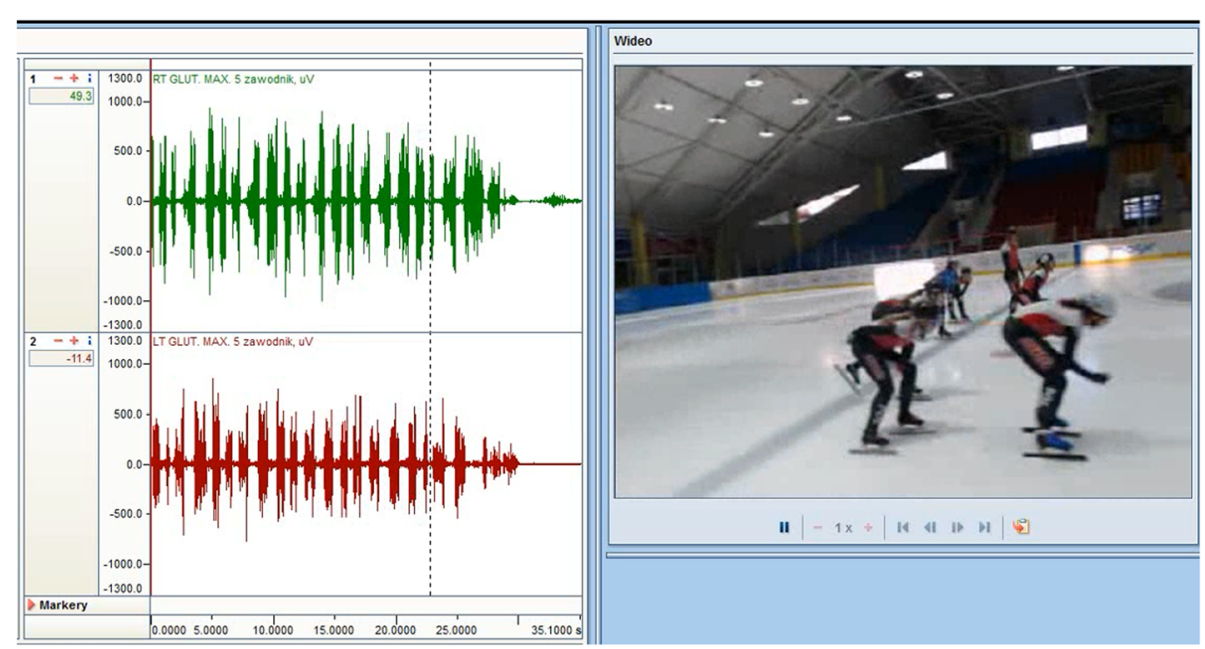

Fig. 3 Exemplary myolectrical manifestations of fatigue slope (raw sEMG records) being a regression coefficient from a linear regression line between the mean frequency and time 


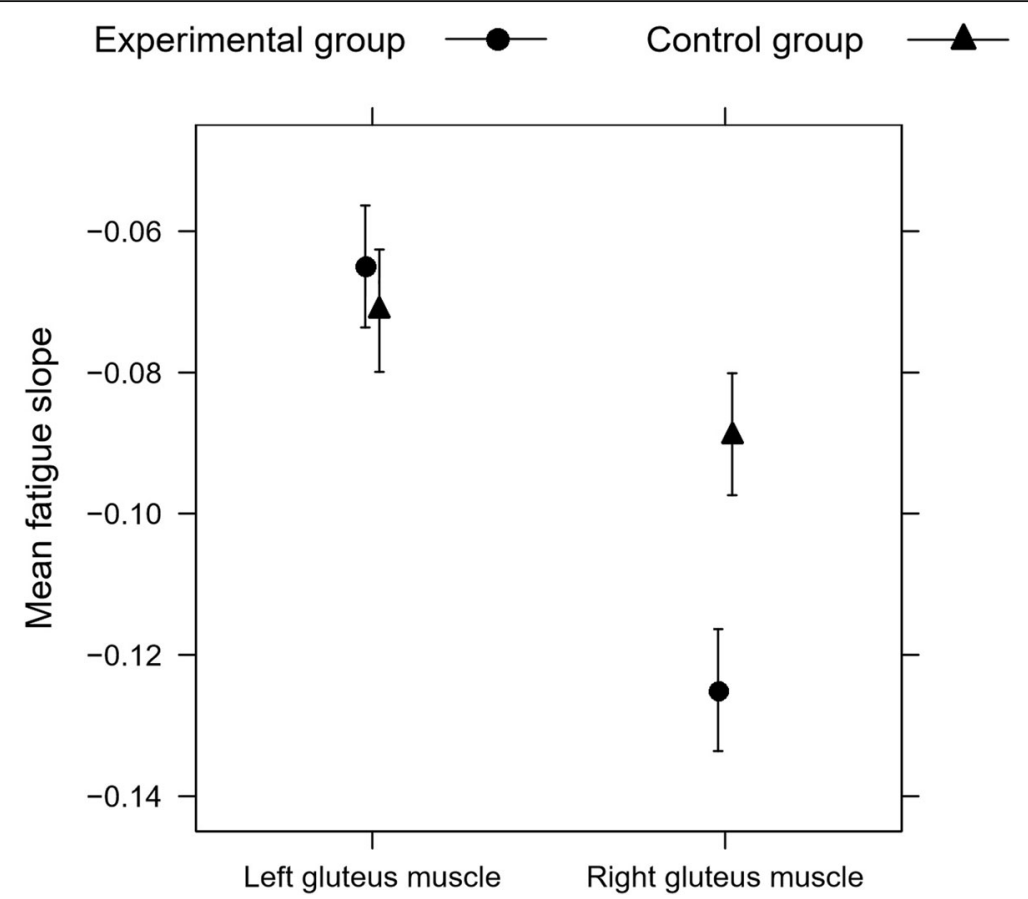

Fig. 4 Mean myolectrical manifestations of fatigue slopes for the right and the left gluteus maximus muscles of the skaters and non-training people (means \pm standard error of the mean from the linear model)

manifestations of fatigue of the left muscle, they did in the myolectrical manifestations of fatigue of the right muscle. The elite speed-track skaters had higher myolectrical manifestations of fatigue in the right muscle than the non-training subjects. Size differences are shown in Fig. 4.

Figure 5 shows significant interactions that indicate that the average slope differences between the right and left muscles differ between the two groups. The more to the left a point lies, the greater the difference between the subject's muscles was. All elite skaters, the asymmetry is visible in the graph (so the points lie far to the left from the zero line). In a non-trained group only a several people had this asymmetry (so only a few points lie far to the left of the zero line). We see thus that the interaction was significant because the groups differed in these differences (representing asymmetry) in the myolectrical manifestations of fatigue of the right and the left muscles.

Figure 6 pairs the left and right maximus gluteus muscles for each subject. This graph clarifies that the non- training subjects who had a small difference in the myolectrical manifestations of fatigue of the muscles had in general low myolectrical manifestations of fatigue of both muscles. While the subjects from the two groups did not differ in the myolectrical manifestations of fatigue of the left muscle, they did in the myolectrical manifestations of fatigue of the right muscle: the elite speed-track skaters had higher myolectrical manifestations of fatigue in the right muscle, and higher than the non-training subjects $(p=0.001$; Table 1 and Figs. 4 and 5).

\section{Discussion}

The research aimed to determine differences in muscle myolectrical manifestations of fatigue in the left and the right maximum gluteus muscles in female short-track skaters and compare these differences with those in healthy non-training women.

What was surprising, however, was so high asymmetry of muscle myolectrical manifestations of fatigue observed in the members of the Polish Women's National Team in short-track speed skating. In general, short-

Table 1 Post-hoc Tukey's tests for the combinations of the groups (skaters and control) and side (left and right muscle)

\begin{tabular}{|c|c|c|c|}
\hline & Skaters, right muscle & Skaters, left muscle & Control, right muscle \\
\hline Skaters, left muscle & $0.001 *$ & & \\
\hline Control, right muscle & $0.029^{*}$ & 0.234 & \\
\hline Control, left muscle & $0.001 *$ & 0.955 & 0.497 \\
\hline
\end{tabular}




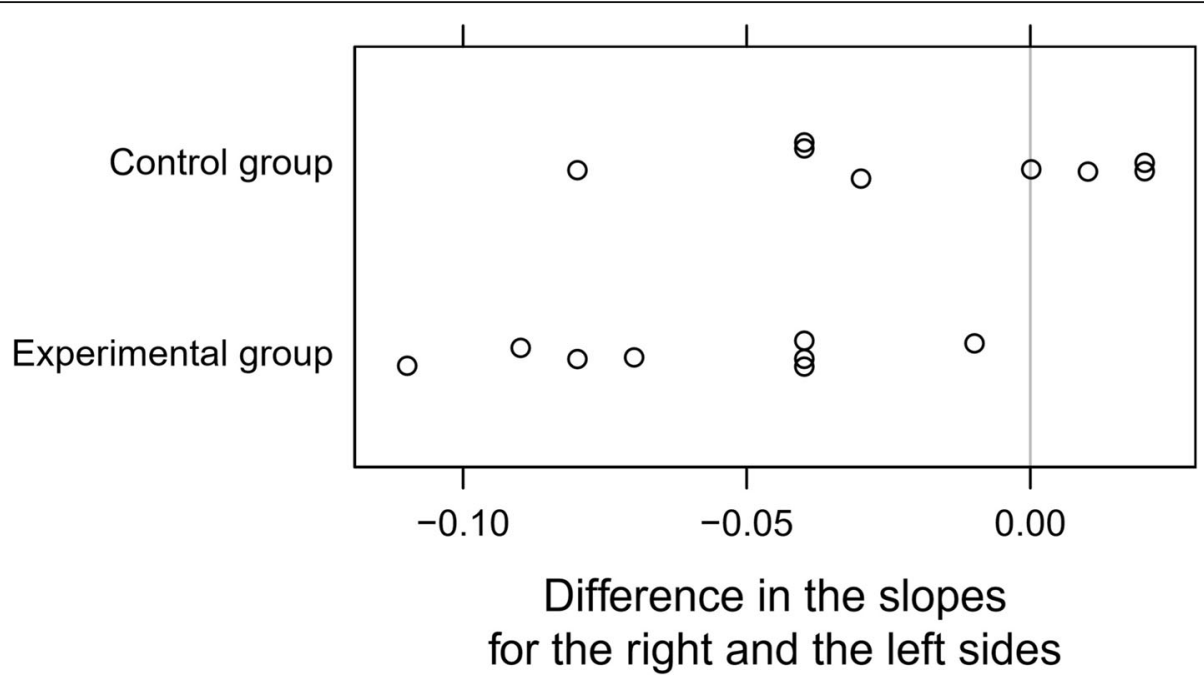

Fig. 5 The differences in the myolectrical manifestations of fatigue slopes between the right and the left gluteus maximus muscles for each subject from the two groups studied. Slight vertical jitter (random noise) was added to avoid the overlap of the points. The grey vertical line represents a no-difference reference point

track training focuses on symmetrical movements, so it should not generate so high asymmetry between the right and the left gluteus maximus muscles. Too high asymmetry in these muscles can increase the risk of injury, so is unfavourable in high-performance athletes [1-3]. thus its importance should not be underestimated in professional sports that involve alternating limb movements.

Such high asymmetry, as in the tested athletes, however, has not been observed in the non-training subjects.
Asymmetry in an experimental group can be caused by specific training in short-track. Small asymmetry in nontraining people is likely a normal phenomenon, and it should not increase the possibility of injury.

Even though experiments without the control group are difficult to interpret, most studies on muscle myolectrical manifestations of fatigue did not include nontraining subjects $[15,16]$. The control group was included in the experiment to analyze muscle asymmetry

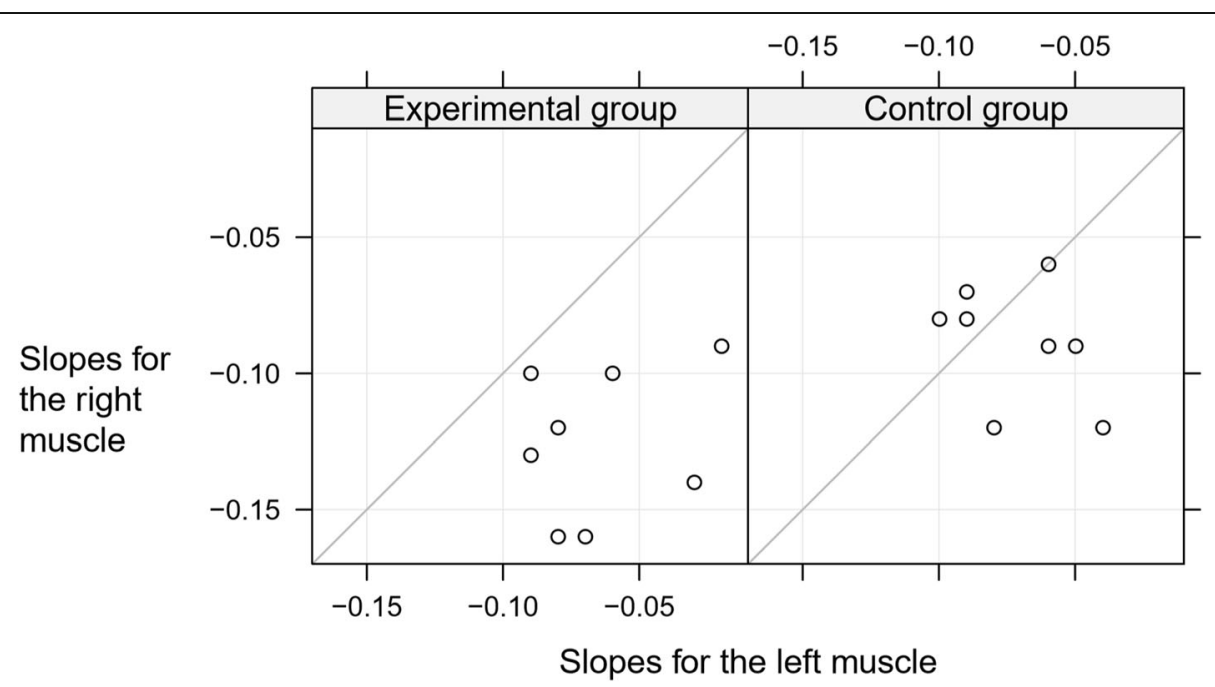

Fig. 6 The myolectrical manifestations of fatigue slopes estimated for the right gluteus maximus muscle versus the slopes estimated for the left muscle, for the two groups. The grey diagonal reference lines represent no difference between the myolectrical manifestations of fatigue slopes for the two muscles. To facilitate the muscle-to-muscle comparison, the vertical and horizontal scales share the minimum and maximum values and have the isometric property. A subject with small myolectrical manifestations of fatigue in both muscles would be represented by a point located in the top right corner of the corresponding panel; a subject with severe myolectrical manifestations of fatigue in both muscles would be represented by a point located in the bottom left corn 
in skaters against the background of non-training people, which did help us draw richer conclusions about the studied phenomenon.

The studied skaters train at a skating rink in about $60 \%$ of the annual training volume, remaining $40 \%$ being focused on symmetrical training of both limbs. Various elements of their individual skating techniques-especially the technique of skating on curves-can cause asymmetry in the gluteus maximus muscles, an unfavourable phenomenon in speed skating because of the increased injury risk it poses. Unfortunately, the phenomenon of muscle asymmetry in professional short-track skaters is still poorly studied, which makes it difficult to design a training process that would not generate asymmetry. Asymmetry in muscle fatigability is certainly not limited to short track, however. Mastalerz et al. [23] reported differences in myolectrical manifestations of fatigue between the muscles of the right and the left legs in runners, reaching from $12,5 \%$ to $26,5 \%$, depending on the muscle Hartz et al. measured the myolectrical manifestations of fatigue index through the induction of shoulder evation movement [24].

Felser et al. showed that muscle tension activity in muscles of both legs differed between the moments of skating in a straight line and in curves; greater differences occurred in the right leg muscles [15]. This result stresses the importance of the cornering technique, likely that element of the training which most strongly increases asymmetry of leg muscles. Hesford et al. also observed asymmetry in legs of though they studied the oxygenation of the quadriceps muscle [16].

\section{Study's limitations}

The limitation of the studies was the size of the experimental group, but due to the specificity of the group, it was not possible to study more athletes.

During the experiment, the skaters were in the middle of the training cycle. On the other hand, the tests were conducted after a weekend break in training, so the muscles were relaxed; had the tests been conducted right after training, the muscles would have been tired, which might have affected the tests. During the gluteal muscle myolectrical manifestations of fatigue research, there was no reference to the activation of other muscles to develop myolectrical manifestations of fatigue. In future studies, it is therefore worth increasing the number of muscles to better investigate the myolectrical manifestations of fatigue process. The sEMG signal frequency change analysis method we used is not a direct method to determine the myolectrical manifestations of fatigue level but only an indirect method.

\section{Conclusions}

Elite female short-track skaters have significant asymmetry in fatigability of the gluteus maximus muscles.

In healthy individuals there is no statistically significant difference in the asymmetry of myolectrical manifestations of fatigue the gluteus maximus muscles.

The results offer an important lesson for the coaches of the Polish Women's National Team in short-track skating.

\section{Abbreviations}

sEMG: Surface electromyography; Ag:/AgCl: Silver chloride electrode; RMS: Root-mean-square; CMR: Common signal rejection

\section{Acknowledgments}

Authors whose names appear on the submission have contributed sufficiently to the scientific work and, therefore, share collective responsibility and accountability for the results.

\section{Authors' contributions}

MK, PP; Responsible for conception and design of the project. MK, PP; Data collection. PP, MW; Performed data analysis, interpreted the data. MK; Drafted, wrote and revised the manuscript. All authors read and approved the final version of the manuscript to be published manuscript.

\section{Funding}

This study would not have been possible without our participants' commitment, time and effort. The research was carried out as part of the statutory activities of the Anthropomotor Department of the Opole University of Technology and was carried out by the researchers of this institution.

\section{Availability of data and materials}

The datasets generated and/or analysed during the current study are not publicly available. However, the data are available from the corresponding author on reasonable request.

\section{Ethics approval and consent to participate}

The tests were previously approved by the Bioethical Commission of the Chamber of Physicians in Opole. (Resolution No. 235 of 13 December 2016). The participants were informed about the purpose and course of tests and signed a consent to participate in the tests.

Consent for publication

Not Applicable.

\section{Competing interests}

The authors declare that they have no competing interests.

\section{Author details}

${ }^{1}$ Faculty of Physical Education and Physiotherapy, Opole University of Technology, Prószkowska 76, 45-758 Opole, Poland. ${ }^{2}$ School of Physical Education and Sport, Adam Mickiewicz University in Poznań, Królowej Jadwigi 27, /39 61-871 Poznań, Poland.

Received: 1 March 2020 Accepted: 21 July 2020

Published online: 14 August 2020

\section{References}

1. Plisky PJ, Rauh MJ, Kaminski TW, Underwood FB. Star excursion balance test as a predictor of lower extremity injury in high school basketball players. J Orthop Sports Phys Ther. 2006;36:911-9..

2. Reeves NP, Cholewicki J, Silfies SP. Muscle activation imbalance and lowback injury in varsity athletes. J Electromyogr Kinesiol. 2006;16:264-72.

3. Fousekis K, Tsepis E, Poulmedis P, Athanasopoulos S, Vagenas G. Intrinsic risk factors of non-contact quadriceps and hamstring strains in soccer: a prospective study of 100 professional players. Br J Sports Med. 2011:45:70914. 
4. Morel B, Rouffet DM, Bishop DJ, Rota SJ, Hautier CA. Fatigue induced by repeated maximal efforts is specific to the Rugby task performed. Int J Sports Sci Coach. 2015;10:11-20.

5. Gandevia SC. Spinal and supraspinal factors in human muscle fatigue. Physiol Rev. 2001;81:1725-89.

6. Tomažin K, Strojnik V, Šarabon N. Changes in surface EMG signal under the influence of peripheral fatigue. Eur J Sport Sci. 2002;2:1-9.

7. Farina D. Interpretation of the surface electromyogram in dynamic contractions. Exerc Sport Sci Rev. 2006;34:121-7.

8. Arendt-Nielsen L, Mills KR. The relationship between mean power frequency of the EMG spectrum and muscle fibre conduction velocity. Electroencephalogr Clin Neurophysiol. 1985;60:130-4.

9. Howard J, Granacher U, Behm DG. Trunk extensor fatigue decreases jump height similarly under stable and unstable conditions with experienced jumpers. Eur J Appl Physiol. 2015;115:285-94.

10. Pitcher MJ, Behm DG, MacKinnon SN. Neuromuscular fatigue during a modified Biering-S??Rensen test in subjects with and without low back pain. J Sport Sci Med. 2007;6:549-59.

11. Coorevits P, Danneels L, Cambier D, Ramon H, Vanderstraeten G. Assessment of the validity of the Biering-Sørensen test for measuring back muscle fatigue based on EMG median frequency characteristics of back and hip muscles. J Electromyogr Kinesiol. 2008;18:997-1005.

12. Champagne A, Descarreaux M, Lafond D. Back and hip extensor muscles fatigue in healthy subjects: task-dependency effect of two variants of the Sorensen test. Eur Spine J. 2008;17:1721-6.

13. Larivière $C$, Gravel $D$, Arsenault $A B$, Gagnon D, Loisel P. Muscle recovery from a short fatigue test and consequence on the reliability of EMG indices of fatigue. Eur J Appl Physiol. 2003:89:171-6.

14. Choi SA, Cynn HS, Yi CH, Kwon OY, Yoon TL, Choi WJ, et al. Isometric hip abduction using a Thera-band alters gluteus maximus muscle activity and the anterior pelvic tilt angle during bridging exercise. J Electromyogr Kinesiol. 2015;25:310-5.

15. Felser S, Behrens M, Fischer S, Baeumler M, Salomon R, Bruhn S. Neuromuscular activation during short-track speed skating in young athletes. Int J Sports Physiol Perform. 2016;11:848-54.

16. Hesford CM, Laing SJ, Cardinale M, Cooper CE. Asymmetry of quadriceps muscle oxygenation during elite short-track speed skating. Med Sci Sports Exerc. 2012:44:501-8.

17. Stoter IK, Macintosh BR, Fletcher JR, Pootz S, Zijdewind I, Hettinga FJ. Pacing strategy, muscle fatigue, and technique in 1500-m speed-skating and cycling time trials. Int J Sports Physiol Perform. 2016;11:337-43.

18. RM, Sepulveda F, Colley M. sEMG Techniques to Detect and Predict Localised Muscle Fatigue. In: EMG Methods for Evaluating Muscle and Nerve Function; 2012.

19. Oskoei MA, Hu H, Gan JQ. Manifestation of fatigue in myoelectric signals of dynamic contractions produced during playing PC games. In: Proceedings of the 30th Annual International Conference of the IEEE Engineering in Medicine and Biology Society, EMBS'08 - "Personalized Healthcare through Technology"; 2008. p. 315-8.

20. Büsch $D$, Hagemann $N$, Bender $N$. The dimensionality of the Edinburgh handedness inventory: an analysis with models of the item response theory. Laterality. 2010;15:610-28.

21. Mutchler JA, Weinhandl JT, Hoch MC, Van Lunen BL. Reliability and fatigue characteristics of a standing hip isometric endurance protocol. J Electromyogr Kinesiol. 2015;25:667-74.

22. Mika A, Oleksy $\measuredangle$, Kielnar R, et al. Comparison of Two Different Modes of Active Recovery on Muscles Performance after Fatiguing Exercise in Mountain Canoeist and Football Players. PLoS One. 2016;11(10):1-14.

23. Mastalerz A, Gwarek L, Sadowski J, Szczepański T. The influence of the run intensity on bioelectrical activity of selected human leg muscles. Acta Bioeng Biomech. 2012;14:101-7.

24. Hartz CS, Pires PF, Moreno MA, Bigaton DR. EMG frequency spectral characteristics of inspiratory accessory muscles during the shoulder lifting motion in throwing athletes. Man Ther Posturology Rehabil J. 2015;13:232.

\section{Publisher's Note}

Springer Nature remains neutral with regard to jurisdictional claims in published maps and institutional affiliations.

Ready to submit your research? Choose BMC and benefit from:

- fast, convenient online submission

- thorough peer review by experienced researchers in your field

- rapid publication on acceptance

- support for research data, including large and complex data types

- gold Open Access which fosters wider collaboration and increased citations

- maximum visibility for your research: over $100 \mathrm{M}$ website views per year

At BMC, research is always in progress.

Learn more biomedcentral.com/submissions 